\title{
Myeloid Cells and Lymphangiogenesis
}

\author{
Adrian Zumsteg and Gerhard Christofori \\ Institute of Biochemistry and Genetics, Department of Biomedicine, University of Basel, \\ $\mathrm{CH}-4058$ Basel, Switzerland \\ Correspondence: gerhard.christofori@unibas.ch
}

The lymphatic vascular system and the hematopoietic system are intimately connected in ontogeny and in physiology. During embryonic development, mammalian species derive a first lymphatic vascular plexus from the previously formed anterior cardinal vein, whereas birds and amphibians have a lymphatic vascular system of dual origin, composed of lymphatic endothelial cells (LECs) of venous origin combined with LECs derived from mesenchymal lymphangioblasts. The contribution of hematopoietic cells as building blocks of nascent lymphatic structures in mammals is still under debate. In contrast, the importance of myeloid cells to direct lymphatic vessel growth and function postnatally has been experimentally shown. For example, myeloid cells communicate with LECs via paracrine factors or cell-cell contacts, and they also can acquire lymphatic endothelial morphology and marker gene expression, a process reminiscent of developmental vasculogenesis. Here, we present an overview of the current understanding of how lymphatic vessels and the hematopoietic system, in particular myeloid cells, interact during embryonic development, in normal organ physiology, and in disease.

\section{THE INTERRELATIONSHIP OF LYMPHATIC ENDOTHELIUM AND HEMATOPOIETIC CELLS DURING DEVELOPMENT}

$T_{\text {lymp }}^{\text {he }}$ he current understanding of the origin of the lymphatic vascular system is that it fully (mammals) or partially (birds, amphibians) originates from venous blood endothelial cells (Oliver 2004). The endothelial system is also, at an earlier stage, giving rise to hematopoietic stem cells, though mainly from arterial structures within the embryo proper and also from extraembryonic structures like the yolk sac and the placenta (Cumano and Godin 2007). The ontological relationship between the hematopoietic and the endothelial system is still under intensive investigation. In mice, definitive hematopoietic stem cells are derived from a socalled hemogenic endothelium. Lineage tracing studies have shown that most leukocytes originate from cells expressing endothelial markers (found on blood vessel endothelial cells [BECs] during development and in the adult), including vascular endothelial growth factor receptor-2 (VEGFR-2), vascular endothelial cadherin (VE-Cadherin) or Tie-2/TEK (Motoike et al. 2003; Li et al. 2006; Chen et al. 2009). Hence, a hematopoietic system cannot be established in the absence of a primitive endothelial system.

The question arises whether, in the converse direction, the hematopoietic system also has an

Editors: Michael Klagsbrun and Patricia D’Amore

Additional Perspectives on Angiogenesis available at www.perspectivesinmedicine.org

Copyright (C) 2012 Cold Spring Harbor Laboratory Press; all rights reserved; doi: 10.1101/cshperspect.a006494

Cite this article as Cold Spring Harb Perspect Med 2012;2:a006494 
influence on the development of the vascular system. Analysis of mice deficient for certain hematopoietic compartments suggests that in the presence of sufficient erythropoiesis and vessel flow most leukocytes are dispensable for the generation of a functional blood and lymphatic vascular system. Several different leukocyte-deficient mouse lines have been established, including lymphocyte-deficient Rag knockout mice (Mombaerts et al. 1992; Shinkai et al. 1992), macrophage-deficient $o p / o p$ mice (Yoshida et al. 1990) and mast celldeficient $\mathrm{Kit}^{\mathrm{W}}{ }^{\mathrm{W}} \mathrm{sh} / \mathrm{W}$-sh -mice (Grimbaldeston et al. 2005); they all display normal blood vessel and lymphatic vessel development. Even in mice deficient for the transcription factor Runxl, which show severely impaired hematopoiesis during development and die in utero, primitive lymph sacs develop normally (Srinivasan et al. 2007). Reports describing mesenchymal cells with macrophage and LEC characteristics within and around developing murine lymphatic vessels nourish the speculation that also in mammals, there may be a dual origin of the lymphatic vascular system (Buttler et al. 2006, 2008). However, functional inactivation of the Prox1 transcription factor in cells derived from the venous endothelium severely impairs lymph sac development, suggesting that Prox1expressing venous endothelial cells are the main source of LECs during lymphatic vasculature development in the mouse (Srinivasan et al. 2007). In addition, lineage-tracing studies using the Vav gene promoter driving Cre-mediated inheritable expression of yellow fluorescent protein (YFP) in definitive hematopoietic cells has not revealed any direct contribution of hematopoietic cells to the formation of lymphatic vessels (Bertozzi et al. 2010).

However, the complete separation of lymphatic sacs from the cardinal veins seems to critically depend on the interaction of the endothelial and the hematopoietic systems. Failure in this separation is apparent by the occurrence of cutaneous hemorrhage during embryonic development and blood-filled lymphatic vessels. This phenotype has been observed in several murine models deficient for genes important for LEC differentiation and identity. For example, the glycoprotein podoplanin expressed on LECs binds the receptor CLEC-2 on platelets to induce platelet aggregation via the activation of a downstream cascade in platelets involving the signaling molecules Syk, Slp-76 and phospholipase-C 2 . Activation of this signaling pathway appears to be crucial for the establishment of separated venous and lymphatic endothelial systems by a thus far unknown mechanism (Abtahian et al. 2003; Bertozzi et al. 2010; Uhrin et al. 2010). However, as podoplanin deficiency reveals a much less severe phenotype than Syk deficiency in mice, there must be additional effects of Syk expression on lymphatic development. Indeed, lineage tracing experiments have identified a Syk-expressing, prolymphangiogenic myeloid population in the skin of murine embryos that was dramatically increased on Syk depletion, leading to lymphatic vessel hyperplasia and blood-lymphatic vessel shunts (Bohmer et al. 2010). These results study suggest that Syk functions in leukocytes to repress the recruitment of prolymphangiogenic myeloid cells to the skin and thus prevents overshooting lymphatic vessel sprouting. In contrast, the lack of macrophages (as seen in $O P / O P$ mice) in skin has no or only a very moderate effect on developmental lymphangiogenesis.

In conclusion, the lymphatic endothelial system in mammals seems to be exclusively derived from the blood endothelial compartment, and the contribution of hematopoietic cells integrating into lymphatic structures is either very small or absent. In contrast, platelet aggregation seems to be indispensable for a correct separation of the lymphatic and the venous endothelial systems.

\section{LEUKOCYTE-MEDIATED REMODELING AND EXPANSION OF LYMPHATIC ENDOTHELIUM}

During embryonic development, the lymphatic vascular system emerges independent of the hematopoietic system with the exception of the platelet-triggered separation of blood and lymphatic vascular structures. However, studies in mice have shown the influence of 
macrophages on postnatal lymphatic vessel development. Analysis of osteopetrotic op/op mice, which are deficient for macrophage colony stimulatory factor (M-CSF) and display markedly reduced osteoclast and macrophage numbers, has revealed that lymphatic vessel branching is reduced in 15-d-old mice by the absence of macrophages in the trachea and the skin and that tissue fluid drainage is impaired in limbs and ears of these mice. Interestingly, lymphatic vessels appear normal in 3-mo-old op/op mice, indicating a role of macrophages in early lymphatic vessel patterning but not in the physiological functions of established lymphatic vessels (Baluk et al. 2005). Accordingly, inhibition of the M-CSF receptor $\mathrm{c}$-fms in adult mice has no measurable effect on the lymphatic vascular system. However, when studying the role of leukocytes during vascular remodeling, one always has to consider that some myeloid cells have been shown to express not only prolymphangiogenic factors, such as VEGF-A, -C, and -D, but also their receptors VEGFR-1 and VEGFR-3. These overlapping expression patterns of receptors and ligands renders the interpretation of experimental results in mouse models difficult, as it will sometimes not be possible to assign the causative cell type.

Infection of the upper respiratory tract in mice by Mycoplasma pulmonis is associated with dramatic architectural changes in the walls of the airways and in the vasculature they contain (Baluk et al. 2005). Within $2 \mathrm{wk}$, blood vessels and lymphatic vessel undergo a dramatic angiogenic expansion. Blood vessel remodeling seems to be driven by the inflammatory function of tumor necrosis factor- $\alpha$ (TNF- $\alpha)$ stimulating its receptor TNFR1, independent of VEGF-A (Baluk et al. 2009). TNFR1 expression is mainly detected on BECs but not on LECs, and the expansion of the lymphatic vasculature in this model has been shown to depend on VEGF-C and/or VEGF-D, classical lymphangiogenic factors (Baluk et al. 2005). In the same model, an unexpected role for adaptive immunity has been discovered: Upon infection of lymphocyte-deficient Rag1-/- mice, the expansion of the blood and lymphatic system was severely compromised as compared to immuno-competent mice. Deposition of immunoglobulin G ( IgG) produced by B cells in a T-cell-dependent manner appears to be essential for vascular remodeling in this model. Notably, IgG deposited at the site of infection may have a role in recruiting and activating infiltrating neutrophils and monocytes (Aurora et al. 2005).

Lymphatic vessel expansion is also critical during infection and inflammation in the skin and their subsequent resolution. Following an inflammatory reaction, the local lymphatic vessels may be less functional due to tissue edema and high leukocyte infiltration. However, within days, afferent lymphatic vessels connecting to draining lymph nodes will expand, thereby acquiring a higher capacity to transport antigens and antigen-presenting cells (APCs) to the lymph nodes. In several different mouse models, it is VEGF-A, the potent blood endothelial mitogenic factor, rather than the lymphangiogenic VEGF-C or D that induces inflammation-mediated lymphangiogenesis. In parallel to the peripheral afferent lymphatic vessels, also within the draining lymph nodes lymphatic vessels proliferate (sinusoidal hyperproliferation). B cells have been shown to be crucially involved in lymph node lymphangiogenesis, because after immunization with keyhole limpet hemocyanin the mitogenic response of lymphatic vessels in the lymph node is diminished in B cell-deficient mice. In fact, $\mathrm{B}$ cells have been identified as a prominent source of VEGF-A (Angeli et al. 2006). In contrast, different inflammatory stimuli (e.g., inducing a delayed type hypersensitivity reaction in ears by oxazolone application) rather identify the inflamed tissue as the primary source of VEGF-A, and lymph node lymphangiogenesis seems a consequence of drainage of VEGF-A to the lymph nodes, independent of B cells (Halin et al. 2007). However, the main source of VEGF is under debate. For example, it has been shown that VEGF-A or VEGF-C expressed as transgenes under the keratinocyte-specific K14 promoter induces tumor lymphangiogenesis and lymph node lymphangiogenesis and promote metastasis to the lymph 
node in chemical carcinogenesis models (Hirakawa et al. 2005, 2006). Conversely, CD11b ${ }^{+} /$ $\mathrm{Grl}^{+}$macrophages infiltrating the skin on application of bacterial polysaccharides are also an important source of VEGF-A, C, and D. Macrophage depletion by treatment with liposome-encapsulated clodronate (Clodrolip) attenuates inflammation-associated cutaneous and lymph node lymphangiogenesis, as well as lymph flow and inflammatory cell transport to the draining lymph nodes (Kataru et al. 2009). A critical role of VEGFR1 tyrosine kinase activity in VEGF-A-mediated macrophage recruitment has been shown by the transplantation of VEGFR1 tyrosine kinase-deficient (Vegfr $1 \mathrm{tk}^{-/-}$) bone marrow cells into mice overexpressing VEGF-A in the ear skin. Macrophage recruitment, lymphangiogenesis, and blood vessel angiogenesis were significantly decreased in mice transplanted with bone marrow cells from Vegfr $1 \mathrm{tk}^{-/-}$mice, as compared to mice transplanted with wild-type bone marrow (Fig. 1) (Murakami et al. 2008). These experiments suggest that VEGF-A expression has different consequences: Locally, it induces angiogenesis, lymphangiogenesis, and vessel permeability. In parallel, it induces recruitment and facilitates extravasation of leukocytes, which are themselves prominent producers of angiogenic factors like VEGF-A, -C, and -D and also deliver inflammatory cytokines like TNF- $\alpha$, which can further increase the local production of VEGF-C and change the expression of endothelial cell adhesion molecules critical for leukocyte adhesion.

In the peritoneum of mice, LECs are also important early players in orchestrating the inflammatory response: Via Toll-like receptor 4 (TLR4) they can sense bacterial lipopolysaccharide (LPS) and through activation of the NF- $\mathrm{BB}$ pathway express leukocyte chemoattractants, such as CCL2, CCL5, and CX3CL1, to promote macrophage homing to the draining lymphatic vessels (Kang et al. 2009). The infiltrating macrophages provide VEGF-C and -D to induce lymphangiogenesis in the peritoneal and the pleural side lymphatic vessels of the diaphragm, as well as in the central tendon and the lymph nodes. Depletion of these macrophages using Clodrolip or trapping of the lymphangiogenic VEGF-C and -D by soluble VEGFR-3 represses this process. Moreover, LPS or TNF- $\alpha$ can induce the expression of the LEC-specific transcription factor Prox-1, followed by Prox-1/NF- $\kappa B$ synergistic promotion of VEGFR-3 expression. Higher levels of VEGFR-3 will render LECs more susceptible to stimulation by suboptimal concentrations of VEGF-C and -D (Flister et al. 2010). Importantly, intraperitoneally injected LPS causes an extremely prominent inflammatory infiltrate in the diaphragm, with increased fibrosis and reduced lymphatic drainage capacity within the lymphatic vessels and to the lymph nodes (Kim et al. 2009). Hence, acute inflammation, even though leading to active lymphangiogenesis, can reduce lymphatic vessel drainage capacity, probably through fibrotic deposits perturbing lymphatic vessel function.

A further challenge for a sole passive role of the lymphatic vascular system in simply offering a transport route for APCs to draining lymph nodes comes from the finding that ICAM-1 on LECs binds to CD11b on dendritic cells (DCs), thereby attenuating DC maturation and the DC's ability to stimulate T-cell proliferation. Importantly, the suppressive effect of the lymphatic endothelium on DCs has been observed only in the absence of pathogen-derived signals (Podgrabinska et al. 2009). This implies that in a steady-state flow of DCs to the lymph nodes, in the absence of a pathogenic signal, the lymphatic endothelium ensures an even-tempered state of the immune system. Conversely, detection of pathogens via Toll-like receptors expressed on LECs ablates their suppressive function on APCs. Also, D6, a scavenger receptor for CC chemokines mainly expressed on LECs, has been shown to modulate the local chemokine microenvironment and by this mechanism control local inflammatory cell infiltration (Nibbs et al. 2007).

Impaired wound healing is a common complication of diabetes, and it has been shown that lymphangiogenesis can be a rate-limiting step during wound healing. Promotion of lymphangiogenesis by delivery of lymphangiogenic growth factors can accelerate wound healing in 


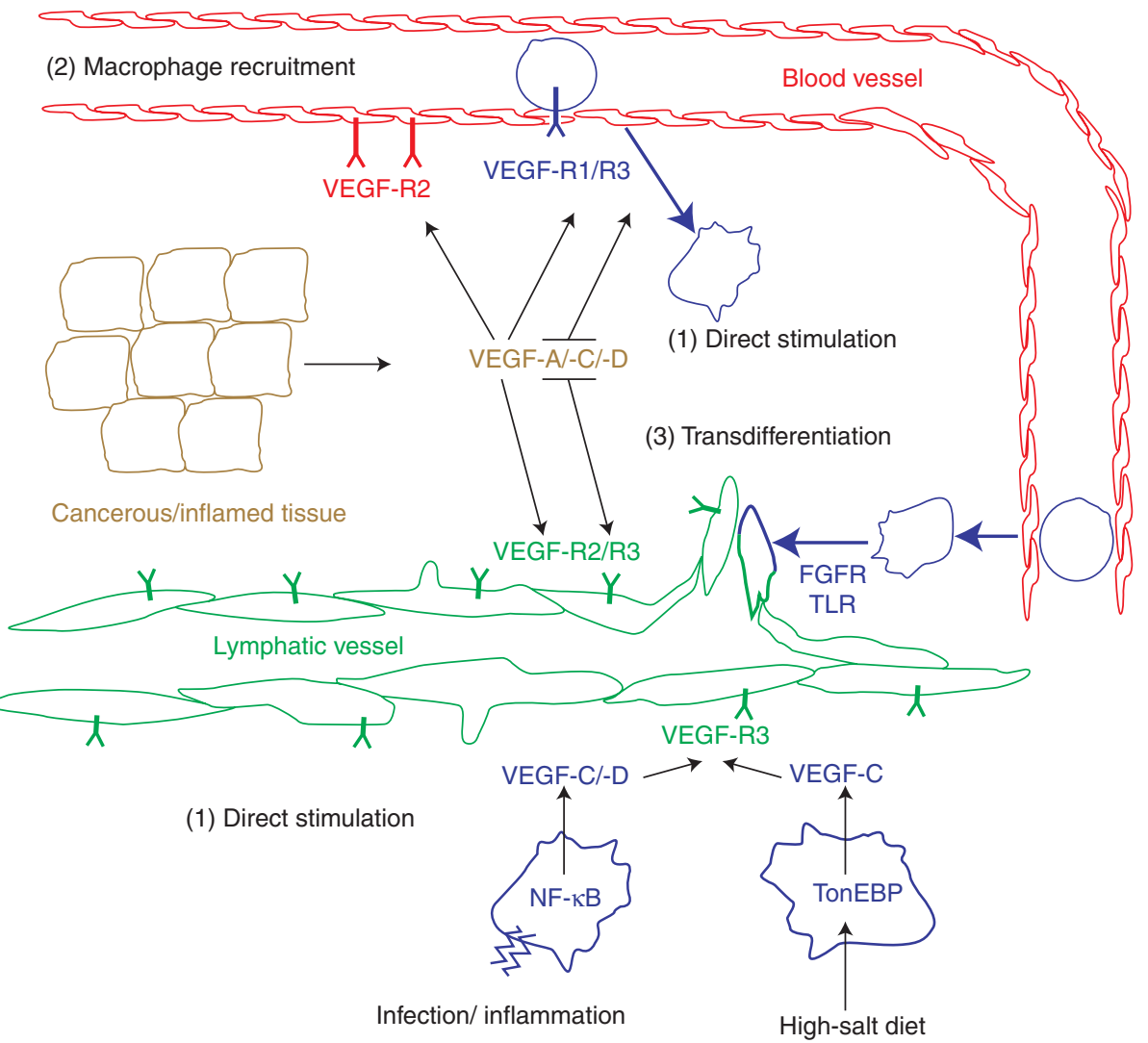

Figure 1. Macrophage involvement in adult pathological lymphangiogenesis. Macrophages contribute in three complementary ways to lymphangiogenesis in pathological situations. (1) Direct stimulation: Inflammation, infection, or high-salt diet can activate VEGF-C and -D expression in tissue-resident macrophages via NF- $\kappa \mathrm{B}$ and TonEBP transcription factors. (2) Immune amplification by angiogenesis-promoting factors. Tissue-derived VEGF-A, -C, and -D can recruit peripheral monocytes via VEGFR-1 and -3. VEGFs also directly stimulate angiogenesis, lymphangiogenesis, and vessel permeability. Recruited monocytes eventually differentiate into macrophages and function as in (1). (3) Peripheral monocytes of unknown polarization can intravasate from the bloodstream into sites of ongoing lymphangiogenesis and integrate into growing lymphatic vessels. In vitro, this conversion is dependent on signaling from Toll-like receptor (TLR) and fibroblast growth factor receptors (FGFR). Monocytes/macrophages are indicated in blue with rugged cell shapes.

an excision skin-wounding model in $d b / d b$ diabetic mice (Saaristo et al. 2006). The investigators have identified an increased recruitment of VEGFR-3-positive macrophages on VEGF-C expression and speculate that the recruited inflammatory cells support wound healing. Other work has subsequently revealed that $d b / d b$ mice have a reduced capacity for macrophage mobilization and that these macrophages are in a hyporeactive state, probably caused by hyperglycemia of the diabetic mice. Activation of hyporeactive macrophages isolated from $d b / d b$ using IL- $1 \beta$ restores their expression of VEGFR-3 and VEGF-C in vitro. When these IL-1 $\beta$-activated macrophages are applied on excision wounds in $d b / d b$ mice, an acceleration of wound closure is observed (Maruyama et al. 2007).

An additional role of macrophages in maintaining skin homeostasis via control of the 
lymphatic vasculature is the regulation of blood pressure. Experimentally induced hypertonic accumulation of $\mathrm{Na}^{+}$in the skin of rats fed a high-salt diet (HSD) leads to hypertension. On an HSD, the mononuclear phagocyte system (MPS), including macrophages and DCs, is orchestrating the expansion of the lymphatic capillary network in the skin (Machnik et al. 2009). Lymphatic capillary density in the skin increases twofold on an HSD, an increase that is paralleled by higher MPS cell density. Importantly, MPS cell depletion using Clodrolip abrogates lymphatic vessel hyperplasia and further increases hypertension. The MPS system therefore regulates a buffering system that attenuates HSD-triggered hypertension. Molecularly, the lymphangiogenic growth factor VEGF-C is induced in MPS cells by the tonicity-responsive enhancer binding protein (TonEBP), which on elevated $\mathrm{Na}^{+}$levels acts as a transcriptional activator. VEGF-C then directly induces lymphatic vessel hyperplasia and the expression of endothelial nitric oxide synthase (eNOS). Mechanistically, increased lymph drainage capacity and eNOS-mediated vasodilation are thought to counteract hypertension (Machnik et al. 2009).

\section{LEUKOCYTES, TUMOR LYMPHANGIOGENESIS, AND LYMPH NODE METASTASIS}

The role of leukocytes in cancer progression has been extensively investigated, and experimental studies in mice and rats as well as histological correlation analysis in patients have firmly established a protumorigenic, proangiogenic branch of the hematopoietic system (Allavena et al. 2008; Zumsteg and Christofori 2009). For example, high levels of tumor-associated macrophages (TAM) in human epithelial tumors usually correlate with poor prognosis, with few exceptions (Bingle et al. 2002). The role of leukocytes, especially of myeloid cells, on tumor lymphangiogenesis has been less intensively studied. Above, we have illustrated the importance of myeloid cells and B cell in different models of inflammatory lymphangiogenesis. The pathologist Rudolf Virchow, already in the 19th century, regarded cancer as "wounds that never heal," anticipating inflammation as an integral part of tumorigenesis. Therefore, many concepts described for inflammation also hold true for the interaction of inflammatory cells and lymphangiogenesis during carcinogenesis.

In human cancer patients, metastatic spreading of tumor cells to regional lymph nodes (sentinel lymph nodes) is considered an important indicator of the likelihood of metastasis to other organs. Correlation studies in human cancers, including breast, head and neck, and melanoma, link the expression of VEGF-C and/or VEGF-D to peritumoral lymphangiogenesis, intralymphatic tumor cell clusters, and lymph node metastasis (Kinoshita et al. 2001; Stacker et al. 2002; Dadras et al. 2005; Siriwardena et al. 2008). Other correlative studies imply inflammatory cells and processes involved in regulation of VEGF-C expression in lymphangiogenesis and lymph node metastasis. For example, VEGF-C expression correlates with COX-2 expression in breast cancer (Zhang et al. 2008), and VEGF-C expression is stimulated by the inflammatory mediators interleukin-1 $\beta$, TNF- $\alpha$, and COX-2 and its induced prostaglandins (Ristimaki et al. 1998; Su et al. 2004). In head and neck cancer, the activity of inducible nitric oxide synthase (iNOS) is found to correlate with VEGF-C expression, lymphangiogenesis, and lymph node metastasis, and the human epidermoid carcinoma cell line A431 up-regulates VEGF-C on nitric oxide (NO) treatment (Franchi et al. 2006). iNOS can be produced by tumor or stromal cells, including macrophages, and is induced by inflammatory cytokines or LPS. Interestingly, iNOS is found to activate COX-2 by S-nitrosylation, thereby enhancing its activity (Kim et al. 2005). As high NO production is a feature of $\mathrm{M} 1$ polarized macrophages, which are antimicrobial and tumoricidal (Allavena et al. 2008), it may be a critical integrator of protective inflammation and subsequent resolution, which also includes lymphangiogenesis.

Inflammatory cells are also a source of lymphangiogenic factors in tumors: In human cervical cancer, a fraction of TAM expresses VEGF-C and D, and the levels of TAM correlate 
with peritumoral lymphatic vessel density. Moreover, naive CD14 monocytes isolated from healthy donors express VEGF-C on TNF- $\alpha$ or LPS stimulation in vitro (Schoppmann et al. 2002). Notably, TAM also express VEGFR-3, and murine peritoneal macrophages are chemoattracted by VEGF-C in transwell assays, attributing VEGF-C also an immunomodulatory function (Skobe et al. 2001).

Experimental studies in mice have shown a direct connection between inflammatory cells and tumor lymphangiogenesis. For example, tumor lymphangiogenesis and lymph node metastasis are repressed with the pharmacological inhibition of COX-2 in mouse models of orthotopic gastric carcinoma and carcinomatous peritonitis (Iwata et al. 2007). Inhibition of COX-2 in macrophages and tumor cells results in a reduction of VEGF-C expression mainly by macrophages. In a closely related model, intraperitoneal injection of human ovarian cancer cell lines in mice induced carcinomatosis and lymphangiogenesis in diaphragm and mesentery (Jeon et al. 2008). However, similar to the situation in LPS-induced peritoneal lymphangiogenesis, this lymphangiogenesis is dysfunctional as assessed by tracer injection into the peritoneum (Kim et al. 2009). A high number of inflammatory cells is observed at the peritoneal side of the diaphragm of these mice, mainly CD $11 b^{+} /$LYVE$^{+} 1^{+}$macrophages expressing VEGF-A, -C, and -D, and depletion of macrophages by Clodrolip reduced the extent of aberrant lymphangiogenesis.

Only few studies employed genetically modified mice to explore the interactions of leukocytes and tumor lymphangiogenesis. In a murine transgenic breast cancer model, macrophages have been shown to be important for the angiogenic switch as well as for promotion of metastasis, as these parameters were severely impaired in $O P / O P$ mice (deficient for most myelomonocytic cell types) as compared to wild-type mice (Lin et al. 2001, 2006). However, effects on tumor lymphangiogenesis have not been assessed. In a subcutaneous osteosarcoma model, inhibition of the M-CSF/c-fms axis by anti-c-fms antibody or by pharmacological inhibition severely reduced macrophage infiltration, tumor angiogenesis, lymphangiogenesis, lymphatic tumor drainage, and metastasis (Kubota et al. 2009).

A critical role in mobilization and recruitment of inflammatory cells to primary tumors and metastatic sites has been assigned to VEGFR-1, also by VEGFR-1-expressing inflammatory cells playing a pivotal role in the development of resistance to antiangiogenic treatment and in preparing the "premetastatic soil” (Kaplan et al. 2005; Bergers et al. 2008). VEGFR-1 is a receptor for the angiogenic growth factors VEGF-A, VEGF-B, and placental growth factor (PlGF), and its function has been implicated in the tumor recruitment of macrophages. In particular, recent studies using anti-PlGF antibodies illustrate that PlGF can be the main factor attracting macrophages to tumors, where they provide angiogenic and lymphangiogenic growth factors (Fischer et al. 2007; Van de Veire et al. 2010). However, the efficacy of anti-PlGF treatment and the molecular mechanisms underlying the repression of tumor angiogenesis is still debated (Bais et al. 2010). For example, B16 melanomas grow to the same extent in mice carrying a nonfunctional VEGFR-1 tyrosine kinase domain (Vegfr1 $\mathrm{tk}^{-/-}$) as compared to wild-type mice, a tumor model that was previously shown to be sensitive to anti-PlGF treatment. Further studies are warranted to resolve this issue.

In conclusion, tumor-associated or tumoractivated leukocytes can actively participate in promoting lymphangiogenesis at the tumor site and within draining lymph nodes, both processes that may facilitate lymph node metastasis. Macrophages can be potent producers of lymphangiogenic growth factors and their depletion in many murine models severely impairs lymphatic vessel function. Macrophages can also trigger the expression of lymphangiogenic growth factors in stromal cells or cancer cells via the secretion of inflammatory cytokines. Overshooting recruitment of inflammatory cells, as seen in models of peritoneal lymphangiogenesis, can result in decreased lymph drainage capacity even in a state of lymphatic vessel hyperplasia. This is 
an important finding, because it uncouples lymphatic vessel density and drainage function at inflammatory sites.

\section{MYELOID-ENDOTHELIAL PLASTICITY IN PATHOLOGICAL INFLAMMATION AND CANCER}

Recent findings have challenged the notion that a cell's identity cannot be changed once differentiated, or can only change along a defined (tissue) stem cell-progenitor cell-differentiated cell axis (e.g., in the hematopoietic system). Experimentally, cells have been converted into different lineages (e.g., somatic cells of various origins into induced pluripotent cells or acinar cells of the pancreas into insulin producing $\beta$-cells) by the forced expression of certain transcription factors (Takahashi et al. 2007; Zhou et al. 2008). Cellular conversions have also been observed in the absence of experimental manipulation (e.g., in metaplasia in which cells convert from one cell type into another with a different morphology and function [Slack 2007]). Also in cancer, epithelial-mesenchymal transition (EMT) is observed, believed to result from a combination of cell intrinsic events (oncogene activation, tumor suppressor function loss) and cell extrinsic factors (e.g., TGF$\beta$ signaling) (Thiery and Sleeman 2006). Such cell plasticity has also been observed in endothelial cells: BECs give rise to fibroblasts that deposit extracellular matrix proteins in a mouse model of cardiac fibrosis in a process referred to as endothelial-mesenchymal transition (Zeisberg et al. 2007). These examples illustrate that conversions from one cell fate into another are likely to be associated with inflammation, a scheme holding true also for the plasticity observed between hematopoietic and (lymph) endothelial cells.

Contribution of hematopoietic cells during embryonic development to the lymphatic endothelial vasculature through processes referred to as transdifferentiation, or transdetermination has not been observed, at least in mice in which stringent lineage-tracing studies are feasible. However, an increasing number of reports show plasticity of myeloid cells in pathophysiological processes. These cells can display a mixed myeloid/endothelial phenotype, they are derived from the bone marrow and they have been functionally and structurally implicated in inflammatory lymphangiogenesis.

The idea that vasculogenesis occurs in adults and not exclusively during embryonic development has been prompted by the finding that bone marrow-derived cells can integrate into growing blood vessels, cells called by their marker profile rather than by their functionality endothelial progenitor cells (EPCs). The initial descriptions of EPCs have been based on the characterization of $\mathrm{CD}_{3}{ }^{+}$(an endothelial marker) cells isolated from blood and cultured under proangiogenic conditions (Asahara et al. 1997). EPC characteristics are now generally thought to reside within the $\mathrm{CD} 14^{+} / \mathrm{CD} 34^{\text {low }}$-monocytic fraction of peripheral (human) blood (Romagnani et al. 2005). The occurrence of lymphvasculogenesis, however, by bone marrow-derived progenitor cells and/or cellular conversion, has been less intensely studied. The identification of a $\mathrm{CD} 133^{+} / \mathrm{VEGFR}^{+} 3^{+}$subfraction of $\mathrm{CD} 34^{+}$ cells in human fetal liver (Salven et al. 2003) and of a CD $14^{+} / \mathrm{VEGFR}^{+}{ }^{+}$subfraction in human peripheral blood (Schoppmann et al. 2002) suggested that (1) during development (and maybe also postnatally) lymphatic endothelial progenitor cells exist, and (2) monocytes $\left(\mathrm{CD} 14^{+}\right)$could be responsive to lymphangiogenic growth factors via their VEGFR-3 expression.

Particularly instructive have been studies undertaken in the cornea and the conjunctiva of the murine eye, which under inflammation show a marked influx of inflammatory cells with robust hemangiogenesis and lymphangiogenesis. The cornea is usually avascular, but under induced inflammatory conditions like cornea transplantation, suturing, electric cautery or angiogenic pellet placement, blood and lymphatic vessels can grow from the conjunctiva through the limbus into the cornea. DCs in the cornea and monocytic cells in the conjunctiva express VEGFR-3 (Hamrah et al. 2003, 2004). Corneal inflammation, triggered by electric cautery, induces a rapid influx of 
CD $11 \mathrm{c}^{+}$DCs into the stroma of the cornea. The dendritic cells then express VEGF-C and also reallocate VEGFR-3 from an intracellular to membranous location (Hamrah et al. 2003). In a similar inflammation model, intrastromal corneal suturing causes a rapid influx of inflammatory $\mathrm{Gr}^{+}$neutrophils and $\mathrm{F} 4 / 80^{+}$macrophages into the cornea, concomitant with activation of hemangiogenesis and lymphangiogenesis (Cursiefen et al. 2004). Depletion of VEGF-A using a receptor trap has diminished recruitment of inflammatory cells and angiogenic responses. Similarly, inhibition of inflammatory cell infiltration, either of all bone marrow-derived cells by irradiation or of monocytic cells by Clodrolip treatment, abolishes angiogenic responses, suggesting a stringent requirement of inflammatory cell infiltration for hemangiogenesis and lymphangiogenesis. $\mathrm{CD}_{1} \mathrm{~b}^{+}$myeloid cells were shown to express VEGF-C and D $48 \mathrm{~h}$ after injury, thus inducing lymphangiogenesis.

Inflammatory cells themselves can also be components of the newly formed lymphatic vessels. In a cornea transplantation model, newly formed corneal LYVE- $1^{+}$lymphatic vessels originate from bone marrow-derived $\mathrm{CD}_{11} \mathrm{~b}^{+}$macrophages and also express the LEC-specific transcription factor Prox-1 (Maruyama et al. 2005). Direct evidence for de novo lymphatic vessel formation is provided by the ex vivo culturing of previously unchallenged, isolated corneas (not containing any endothelial cells but $\mathrm{CD} 1 \mathrm{~b}^{+}$myeloid cells), which under IL1 $\beta$ stimulation develop LYVE- $1^{+} / \mathrm{CD} 31^{+}$structures in absence of any connected endothelial structure. This study and a second one, placing FGF2-loaded micropellets in corneas, also show integration of bone marrow-derived cells into newly formed lymphatic vessels in the cornea, illustrating the rapid mobilization of bone marrow cells and recruitment to the cornea on inflammation (Religa et al. 2005).

Also in humans, there is evidence for recruitment of lymphatic endothelial progenitor cells during lymphangiogenesis. An elegant retrospective study with sex-mismatched, rejected kidney transplants shows the integration of recipient-derived cells into lymphatic vessels, constituting about $4.5 \%$ of all LECs in the rejected organ (Kerjaschki et al. 2006). Contrary, in control organs of sex-mismatched bone marrow transplantation recipients, neither intestinal nor skin lymphatic vessels showed integration of bone marrow-derived cells (Fig. 2). Along these lines, in biopsies of human Onchocerca (a filarial nematode causing skin disease and river blindness) nodules, LYVE-1-positive macrophages were identified integrated into lymphatic vessels in the fibrous capsule of the nodule (Attout et al. 2009). Finally, in human idiopathic pulmonary fibrosis, alveolar lymphangiogenesis correlates with the disease severity. $\mathrm{CD}_{11 \mathrm{~b}^{+}}$macrophages from bronchoalveolar lavage fluid from pulmonary fibrosis patients, but not from healthy subjects, are able to form tube like structures in vitro expressing the LEC markers LYVE-1 and podoplanin (El-Chemaly et al. 2009). These results indicate that inflammation is a prerequisite for the potential transdifferentiation of myeloid cells into LECs.

The contribution of bone marrow-derived cells to tumor lymphangiogenesis is very controversial. In mice subcutaneously transplanted with B16F1 melanoma and Lewis lung carcinoma and previously transplanted with genetically labeled bone marrow, no integration of bone marrow-derived cells into tumor-associated lymphatic vessels has been observed ( $\mathrm{He}$ et al. 2004). In contrast, contribution of bone marrow cells has been observed in subcutaneous T241 fibrosarcoma tumors and in the genetic $\mathrm{Apc}^{\mathrm{Min} /+}$ model of intestinal adenoma (Religa et al. 2005; Jiang et al. 2008). In the transgenic Rip1Tag2 mouse model of pancreatic $\beta$-cell carcinogenesis and in subcutaneously grown TRAMP-C1 prostate adenocarcinoma, a combination of adoptive bone marrow transfer and genetic lineage tracing experiments has revealed that bone marrow-derived cells of the myeloid lineage integrate into tumorassociated lymphatic vessels (Zumsteg et al. 2009). Furthermore, in vitro differentiated macrophages are able to aggregate into lymphatic like structures and, while losing the expression of macrophage markers, to express LEC 
A. Zumsteg and G. Christofori

A Bone marrow transplantation
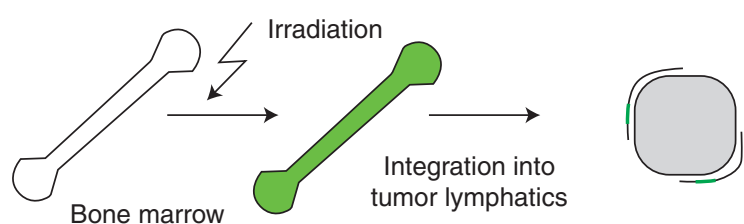

ransplantation

(GFP labeled)

Integration into tumor lymphatics

Lineage tracing

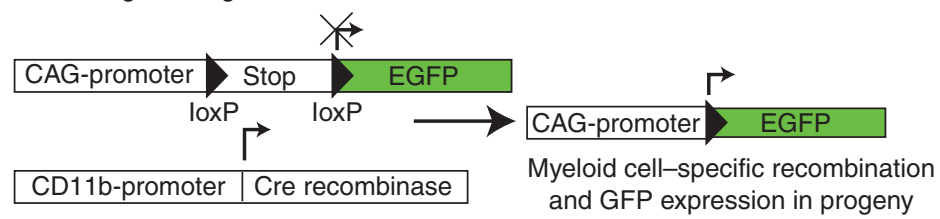

B

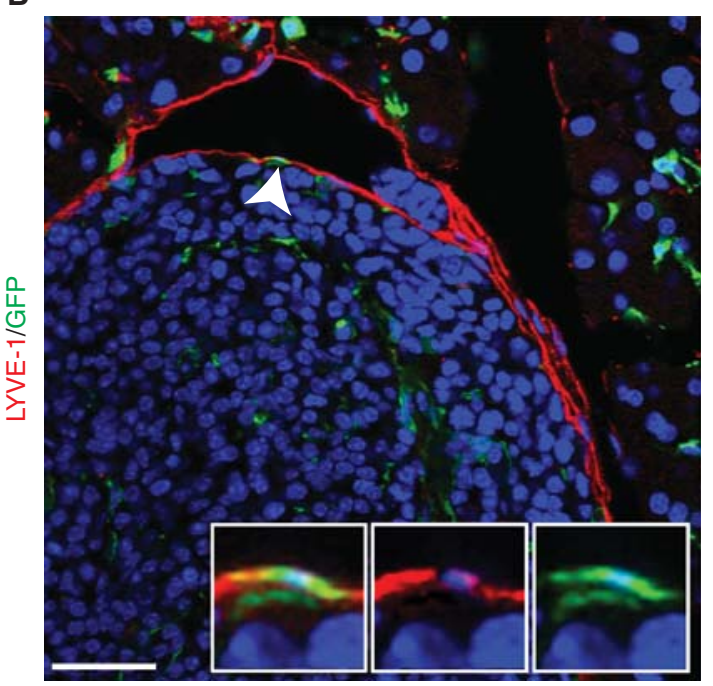

Figure 2. Experimental demonstration of monocyte-lymphatic endothelial plasticity. $(A)$ Transplantation of GFP-labeled bone marrow is a strategy to identify bone marrow-derived cells in diverse tissues of the recipient, including tumors. Alternatively, using Cre/Lox-mediated lineage-tracing strategy, myeloid cells expressing Cre recombinase under the myeloid specific CD11b promoter can activate a GFP reporter transgene and thus label all cells that have been passed through a CD11b-expressing lineage. Bone marrow transplantation and lineage tracing can also be combined. (B) Transplantation of GFP-labeled bone marrow into double-transgenic Rip1Tag2;Rip-VEGF-C mice that develop pancreatic $\beta$-cell tumors with a high extent of peritumoral lymphangiogenesis and lymph node metastasis. A histological section has been stained with antibodies against the lymphatic marker LYVE-1 (red) and GFP (green). DAPI staining visualizes nuclei (blue). Note a GFP ${ }^{+}$, bone marrow-derived cell (green) integrated in a tumor-surrounding LYVE- $1^{+}$lymphatic vessel (red), as indicated by an arrowhead and shown in higher-magnification insets. 
markers, such as podoplanin, LYVE-1, Prox1, and FoxC2. The molecular link between inflammation and the transdifferentiation potential of macrophages, however, is only poorly understood.

What could be the role of macrophages acquiring lymphatic endothelial characteristic in inflammation, be it tissue wounding or in cancer? One speculation is that macrophages can de novo form lymphatic tubes in previously avascular organs, such as the cornea, to speed up immune reactions and overcome the very slow ingrowth of distant lymphatic vessels by sprouting lymphangiogenesis. The presence of macrophages in basically all organs and their fast mobilization and replenishment makes these cells ideally suited for this task. Another function could be to support endothelial sprouting, as macrophages are a rich source of proteinases that are needed to degrade the ECM. This guidance might be more efficient when macrophages employ homotypic interactions with their followers, like the expression of VE-cadherin. Normally, macrophages and other APCs are designed to transmigrate through endothelial sheets, and only the acquisition of lymphatic traits may allow stable integration of macrophages into a lymphatic endothelial cell collective.

In conclusion, this article indicates that macrophages may serve a dual role in lymphangiogenesis, either acting directly as lymphatic endothelial progenitors or indirectly by providing lymphangiogenic growth factors. Because monocytes/macrophages are sensitive to stimuli directly promoting angiogenesis and lymphangiogenesis, they can potentiate initially weak proangiogenic signaling cues and, thus, may offer an appropriate target for the design of antiangiogenic and antilymphangiogenic therapy.

\section{ACKNOWLEDGMENTS}

We apologize to all colleagues whose important work we could not cite due to space restrictions. Research in the laboratory of the authors related to this review article has been supported by the NCCR Molecular Oncology of the Swiss
National Science Foundation, the EU-FP6 framework programme LYMPHANGIOGENOMICS LSHG-CT-2004-503573, and the Swiss National Science Foundation.

\section{REFERENCES}

Abtahian F, Guerriero A, Sebzda E, Lu MM, Zhou R, Mocsai A, Myers EE, Huang B, Jackson DG, Ferrari VA, et al. 2003. Regulation of blood and lymphatic vascular separation by signaling proteins SLP-76 and Syk. Science 299: 247-251.

Allavena P, Sica A, Solinas G, Porta C, Mantovani A. 2008. The inflammatory micro-environment in tumor progression: The role of tumor-associated macrophages. Crit Rev Oncol Hematol 66: 1-9.

Angeli V, Ginhoux F, Llodra J, Quemeneur L, Frenette PS, Skobe M, Jessberger R, Merad M, Randolph GJ. 2006. B cell-driven lymphangiogenesis in inflamed lymph nodes enhances dendritic cell mobilization. Immunity 24: 203-215.

Asahara T, Murohara T, Sullivan A, Silver M, van der Zee R, Li T, Witzenbichler B, Schatteman G, Isner JM. 1997. Isolation of putative progenitor endothelial cells for angiogenesis. Science 275: 964-967.

Attout T, Hoerauf A, Denece G, Debrah AY, MarfoDebrekyei Y, Boussinesq M, Wanji S, Martinez V, Mand S, Adjei O, et al. 2009. Lymphatic vascularisation and involvement of Lyve- $1^{+}$macrophages in the human onchocerca nodule. PLoS One 4: e8234.

Aurora AB, Baluk P, Zhang D, Sidhu SS, Dolganov GM, Basbaum C, McDonald DM, Killeen N. 2005. Immune complex-dependent remodeling of the airway vasculature in response to a chronic bacterial infection. J Immunol 175: 6319-6326.

Bais C, Wu X, Yao J, Yang S, Crawford Y, McCutcheon K, Tan C, Kolumam G, Vernes JM, Eastham-Anderson J, et al 2010. PlGF blockade does not inhibit angiogenesis during primary tumor growth. Cell 141: 166-177.

Baluk P, Tammela T, Ator E, Lyubynska N, Achen MG, Hicklin DJ, Jeltsch M, Petrova TV, Pytowski B, Stacker SA, et al. 2005. Pathogenesis of persistent lymphatic vessel hyperplasia in chronic airway inflammation. J Clin Invest 115: $247-257$.

Baluk P, Yao LC, Feng J, Romano T, Jung SS, Schreiter JL, Yan L, Shealy DJ, McDonald DM. 2009. TNF- $\alpha$ drives remodeling of blood vessels and lymphatics in sustained airway inflammation in mice. J Clin Invest 119: 2954-2964.

Bergers G, Hanahan D. 2008. Modes of resistance to antiangiogenic therapy. Nat Rev Cancer 8: 592-603.

Bertozzi CC, Schmaier AA, Mericko P, Hess PR, Zou Z, Chen M, Chen CY, Xu B, Lu MM, Zhou D, et al. 2010. Platelets regulate lymphatic vascular development through CLEC-2-SLP-76 signaling. Blood 116: 661-670.

Bingle L, Brown NJ, Lewis CE. 2002. The role of tumourassociated macrophages in tumour progression: Implications for new anticancer therapies. J Pathol 196: 254-265.

Bohmer R, Neuhaus B, Buhren S, Zhang D, Stehling M, Bock B, Keifer F. 2010. Regulation of developmental 
lymphangiogenesis by $\mathrm{Syk}^{+}$leukocytes. Dev Cell 18: 437-449.

Buttler K, Kreysing A, von Kaisenberg CS, Schweigerer L, Gale N, Papoutsi M, Wilting J. 2006. Mesenchymal cells with leukocyte and lymphendothelial characteristics in murine embryos. Dev Dyn 235: 1554-1562.

Buttler K, Ezaki T, Wilting J. 2008. Proliferating mesodermal cells in murine embryos exhibiting macrophage and lymphendothelial characteristics. BMC Dev Biol 8: 43.

Chen MJ, Yokomizo T, Zeigler BM, Dzierzak E, Speck NA. 2009. Runx1 is required for the endothelial to haematopoietic cell transition but not thereafter. Nature 457: 887-891.

Cumano A, Godin I. 2007. Ontogeny of the hematopoietic system. Annu Rev Immunol 25: 745-785.

Cursiefen C, Chen L, Borges LP, Jackson D, Cao J, Radziejewski C, D'Amore PA, Dana MR, Weigand SJ, Streilein JW. 2004. VEGF-A stimulates lymphangiogenesis and hemangiogenesis in inflammatory neovascularization via macrophage recruitment. J Clin Invest 113: 1040 1050.

Dadras SS, Lange-Asschenfeldt B, Velasco P, Nguyen L, Vora A, Muzikansky A, Jahnke K, Hauschild A, Hirakawa S, Mihm MC, et al. 2005. Tumor lymphangiogenesis predicts melanoma metastasis to sentinel lymph nodes. Mod Pathol 18: 1232-1242.

El-Chemaly S, Malide D, Zudaire E, Ikeda Y, Weinberg BA, Pacheco-Rodriguez G, Rosas IO, Aparicio M, Ren P, MacDonald SD, et al. 2009. Abnormal lymphangiogenesis in idiopathic pulmonary fibrosis with insights into cellular and molecular mechanisms. Proc Natl Acad Sci 106: 3958-3963.

Fischer C, Jonckx B, Mazzone M, Zacchigna S, Loges S, Pattarini L, Chorianopoulos E, Liesenborghs L, Koch M, De Mol M, et al. 2007. Anti-PlGF inhibits growth of VEGF(R)-inhibitor-resistant tumors without affecting healthy vessels. Cell 131: 463-475.

Flister MJ, Wilber A, Hall KL, Iwata C, Miyazono K, Nisato RE, Pepper MS, Zawieja DC, Ran S. 2010. Inflammation induces lymphangiogenesis through up-regulation of VEGFR-3 mediated by NF- $\mathrm{kB}$ and Prox1. Blood 115: 418-429.

Franchi A, Massi D, Santucci M, Masini E, Degl'Innocenti DR, Magnelli L, Fanti E, Naldini A, Ardinghi C, Carraro F, et al. 2006. Inducible nitric oxide synthase activity correlates with lymphangiogenesis and vascular endothelial growth factor-C expression in head and neck squamous cell carcinoma. J Pathol 208: 439-445.

Grimbaldeston MA, Chen CC, Piliponsky AM, Tsai M, Tam SY, Galli SJ. 2005. Mast cell-deficient W-sash c-kit mutant $K i t^{W-s h / W-s h}$ mice as a model for investigating mast cell biology in vivo. Am J Pathol 167: 835-848.

Halin C, Tobler NE, Vigl B, Brown LF, Detmar M. 2007. VEGF-A produced by chronically inflamed tissue induces lymphangiogenesis in draining lymph nodes. Blood 110: 3158-3167.

Hamrah P, Chen L, Zhang Q, Dana MR. 2003. Novel expression of vascular endothelial growth factor receptor (VEGFR)-3 and VEGF-C on corneal dendritic cells. Am J Pathol 163: 57-68.

Hamrah P, Chen L, Cursiefen C, Zhang Q, Joyce NC, Dana MR. 2004. Expression of vascular endothelial growth factor receptor-3 (VEGFR-3) on monocytic bone marrow-derived cells in the conjunctiva. Exp Eye Res 79: $553-561$.

He Y, Rajantie I, Ilmonen M, Makinen T, Karkkainen MJ, Haiko P, Salven P, Alitalo K. 2004. Preexisting lymphatic endothelium but not endothelial progenitor cells are essential for tumor lymphangiogenesis and lymphatic metastasis. Cancer Res 64: 3737-3740.

Hirakawa S, Kodama S, Kunstfeld R, Kajiya K, Brown LF Detmar M. 2005. VEGF-A induces tumor and sentinel lymph node lymphangiogenesis and promotes lymphatic metastasis. J Exp Med 201: 1089-1099.

Hirakawa S, Brown LF, Kodama S, Paavonen K, Alitalo K, Detmar M. 2006. VEGF-C-induced lymphangiogenesis in sentinel lymph nodes promotes tumor metastasis to distant sites. Blood 109: 1010-1017.

Iwata C, Kano MR, Komuro A, Oka M, Kiyono K, Johansson E, Morishita Y, Yashiro M, Hirakawa K, Kaminishi M, et al. 2007. Inhibition of cyclooxygenase-2 suppresses lymph node metastasis via reduction of lymphangiogenesis. Cancer Res 67: 10181-10189.

Jeon BH, Jang C, Han J, Kataru RP, Piao L, Jung K, Cha HJ, Schwendener RA, Jang KY, Kim KS, et al. 2008. Profound but dysfunctional lymphangiogenesis via vascular endothelial growth factor ligands from $\mathrm{CD}_{11} \mathrm{~b}^{+}$macrophages in advanced ovarian cancer. Cancer Res 68: 1100-1109.

Jiang S, Bailey AS, Goldman DC, Swain JR, Wong MH, Streeter PR, Fleming WH. 2008. Hematopoietic stem cells contribute to lymphatic endothelium. PLOS ONE 3: e3812.

Kang S, Lee SP, Kim KE, Kim HZ, Memet S, Koh GY. 2009. Toll-like receptor 4 in lymphatic endothelial cells contributes to LPS-induced lymphangiogenesis by chemotactic recruitment of macrophages. Blood 113: 2605-2613.

Kaplan RN, Riba RD, Zacharoulis S, Bramley AH, Vincent L, Costa C, MacDonald DD, Jin DK, Shido K, Kerns SA, et al. 2005. VEGFR1-positive haematopoietic bone marrow progenitors initiate the pre-metastatic niche. Nature 438: $820-827$.

Kataru RP, Jung K, Jang C, Yang H, Schwendener RA, Baik JE, Han SH, Alitalo K, Koh GY. 2009. Critical role of $\mathrm{CD}_{1} \mathrm{~b}^{+}$macrophages and VEGF in inflammatory lymphangiogenesis, antigen clearance, and inflammation resolution. Blood 113: 5650-5659.

Kerjaschki D, Huttary N, Raab I, Regele H, Bojarski-Nagy K, Bartel G, Krober SM, Greinix H, Rosenmaier A, Karlhofer F, et al. 2006. Lymphatic endothelial progenitor cells contribute to de novo lymphangiogenesis in human renal transplants. Nat Med 12: 230-234.

Kim SF, Huri DA, Snyder SH. 2005. Inducible nitric oxide synthase binds, S-nitrosylates, and activates cyclooxygenase-2. Science 310: 1966-1970.

Kim KE, Koh YJ, Jeon BH, Jang C, Han J, Kataru RP, Schwendener RA, Kim JM, Koh GY. 2009. Role of $\mathrm{CD} 1 \mathrm{~b}^{+}$macrophages in intraperitoneal lipopolysaccharide-induced aberrant lymphangiogenesis and lymphatic function in the diaphragm. Am J Pathol 175: 1733-1745.

Kinoshita J, Kitamura K, Kabashima A, Saeki H, Tanaka S, Sugimachi K. 2001. Clinical significance of vascular endothelial growth factor-C (VEGF-C) in breast cancer. Breast Cancer Res Treat 66: 159-164. 
Kubota Y, Takubo K, Shimizu T, Ohno H, Kishi K, Shibuya M, Saya H, Suda T. 2009. M-CSF inhibition selectively targets pathological angiogenesis and lymphangiogenesis. J Exp Med 206: 1089-1102.

Li Z, Chen MJ, Stacy T, Speck NA. 2006. Runx1 function in hematopoiesis is required in cells that express Tek. Blood 107: $106-110$.

Lin EY, Nguyen AV, Russell RG, Pollard JW. 2001. Colonystimulating factor 1 promotes progression of mammary tumors to malignancy. J Exp Med 193: 727-740.

Lin EY, Li JF, Gnatovskiy L, Deng Y, Zhu L, Grzeski DA, Qian H, Xue XN, Pollard JW. 2006. Macrophages regulate the angiogenic switch in a mouse model of breast cancer. Cancer Res 66: 11238-11246.

Machnik A, Neuhofer W, Jantsch J, Dahlmann A, Tammela T, Machura K, Park JK, Beck FX, Muller DN, Deer W, et al. 2009. Macrophages regulate salt-dependent volume and blood pressure by a vascular endothelial growth factor-C-dependent buffering mechanism. Nat Med 15: $545-552$.

Maruyama K, Ii M, Cursiefen C, Jackson DG, Keino H, Tomita M, Van Rooijen N, Takenaka H, D'Amore PA, Stein-Streilein J, et al. 2005. Inflammation-induced lymphangiogenesis in the cornea arises from CD11b-positive macrophages. J Clin Invest 115: 2363-2372.

Maruyama K, Asai J, Ii M, Thorne T, Losordo DW, D’Amore PA. 2007. Decreased macrophage number and activation lead to reduced lymphatic vessel formation and contribute to impaired diabetic wound healing. Am J Pathol 170: $1178-1191$.

Mombaerts P, Iacomini J, Johnson RS, Herrup K, Tonegawa S, Papaioannou VE. 1992. RAG-1-deficient mice have no mature B and T lymphocytes. Cell 68: 869-877.

Motoike T, Markham DW, Rossant J, Sato TN. 2003. Evidence for novel fate of $\mathrm{Flk}^{+}$progenitor: Contribution to muscle lineage. Genesis 35: 153-159.

Murakami M, Zheng Y, Hirashima M, Suda T, Moriat Y, Ooehara J, Ema H, Fong GH, Shibuya M. 2008. VEGFR1 tyrosine kinase signaling promotes lymphangiogenesis as well as angiogenesis indirectly via macrophage recruitment. Arterioscler Thromb Vasc Biol 28: 658-664.

Nibbs RJ, Gilchrist DS, King V, Ferra A, Forrow S, Hunter KD, Graham GJ. 2007. The atypical chemokine receptor D6 suppresses the development of chemically induced skin tumors. J Clin Invest 117: 1884-1892.

Oliver G. 2004. Lymphatic vasculature development. Nat Rev Immunol 4: 35-45.

Podgrabinska S, Kamalu O, Mayer L, Shimaoka M, Snoeck H, Randolph GJ, Skobe M. 2009. Inflamed lymphatic endothelium suppresses dendritic cell maturation and function via Mac-1/ICAM-1-dependent mechanism. J Immunol 183: 1767-1779.

Religa P, Cao R, Bjorndahl M, Zhou Z, Zhu Z, Cao Y. 2005. Presence of bone marrow-derived circulating progenitor endothelial cells in the newly formed lymphatic vessels. Blood 106: 4184-4190.

Ristimaki A, Narko K, Enholm B, Joukov V, Alitalo K. 1998. Proinflammatory cytokines regulate expression of the lymphatic endothelial mitogen vascular endothelial growth factor-C. J Biol Chem 273: 8413-8418.
Romagnani P, Annunziato F, Liotta F, Lazzeri E, Mazzinghi B, Frosali F, Cosmi L, Maggi L, Lasagni L, Scheffold A, et al. 2005. CD14 ${ }^{+} \mathrm{CD} 34$ low cells with stem cell phenotypic and functional features are the major source of circulating endothelial progenitors. Circ Res 97: 314-322.

Saaristo A, Tammela T, Farkkilä A, Kärkkäinen M, Suominen E, Yla-Hertuala S, Alitalo K. 2006. Vascular endothelial growth factor-C accelerates diabetic wound healing. Am J Pathol 169: 1080-1087.

Salven P, Mustjoki S, Alitalo R, Alitalo K, Rafii S. 2003. VEGFR-3 and CD133 identify a population of CD34 ${ }^{+}$ lymphatic/vascular endothelial precursor cells. Blood 101: $168-172$.

Schoppmann SF, Birner P, Stockl J, Kalt R, Ullrich R, Caucig C, Kriehuber E, Nagy K, Alitalo K, Kerjaschki D. 2002. Tumor-associated macrophages express lymphatic endothelial growth factors and are related to peritumoral lymphangiogenesis. Am J Pathol 161: 947-956.

Shinkai Y, Rathbun G, Lam KP, Oltz EM, Stewart V, Mendelsohn M, Charron J, Datta M, Young F, Stall AM, et al. 1992. RAG-2-deficient mice lack mature lymphocytes owing to inability to initiate $\mathrm{V}(\mathrm{D}) \mathrm{J}$ rearrangement. Cell 68: $855-867$.

Siriwardena BS, Kudo Y, Ogawa I, Udagama MN, Tilakaratne WM, Takata T. 2008. VEGF-C is associated with lymphatic status and invasion in oral cancer. J Clin Pathol 61: 103-108.

Skobe M, Hamberg LM, Hawighorst T, Schirner M, Wolf GL, Alitalo K, Detmar M. 2001. Concurrent induction of lymphangiogenesis, angiogenesis, and macrophage recruitment by vascular endothelial growth factor- $\mathrm{C}$ in melanoma. Am J Pathol 159: 893-903.

Slack JM. 2007. Metaplasia and transdifferentiation: From pure biology to the clinic. Nat Rev Mol Cell Biol 8: 369-378.

Srinivasan RS, Dillard ME, Lagutin OV, Lin FJ, Tsai S, Tsai MJ, Samokhvalov IM, Oliver G. 2007. Lineage tracing demonstrates the venous origin of the mammalian lymphatic vasculature. Genes Dev 21: 2422-2432.

Stacker SA, Achen MG, Jussila L, Baldwin ME, Alitalo K. 2002. Lymphangiogenesis and cancer metastasis. Nat Rev Cancer 2: 573-583.

Su JL, Shih JY, Yen ML, Jeng YM, Chang CC, Hsieh CY, Wie LH, Yang PC, Kuo ML. 2004. Cyclooxygenase-2 induces EP1- and HER-2/Neu-dependent vascular endothelial growth factor-C up-regulation: A novel mechanism of lymphangiogenesis in lung adenocarcinoma. Cancer Res 64: 554-564.

Takahashi K, Tanabe K, Ohnuki M, Narita M, Ichisaka T, Tomoda K, Yamanaka S. 2007. Induction of pluripotent stem cells from adult human fibroblasts by defined factors. Cell 131: 861-872.

Thiery JP, Sleeman JP. 2006. Complex networks orchestrate epithelial-mesenchymal transitions. Nat Rev Mol Cell Biol 7: 131-142.

Uhrin P, Zaujec J, Breuss JM, Olcaydu D, Chrenek P, Stockinger H, Fuertbauer E, Moser M, Haiko P, Fassler R, et al. 2010. Novel function for blood platelets and podoplanin in developmental separation of blood and lymphatic circulation. Blood 115: 3997-4005.

Van de Veire S, Stalmans I, Heindryckx F, Oura H, TijerasRaballand A, Schmidt T, Loges S, Albrecht I, Jonckx B, 


\section{A. Zumsteg and G. Christofori}

Vinckier S, et al. 2010. Further pharmacological and genetic evidence for the efficacy of PlGF inhibition in cancer and eye disease. Cell 141: 178-190.

Yoshida H, Hayashi S, Kunisada T, Ogawa M, Nishikawa S, Okamura H, Sudo T, Shultz LD, Nishikawa S. 1990. The murine mutation osteopetrosis is in the coding region of the macrophage colony stimulating factor gene. Nature 345: 442-444.

Zeisberg EM, Tarnavski O, Zeisberg M, Dorfman AL, McMullen JR, Gustafsson E, Chandraker A, Yuan X, Pu WT, Roberts AB, et al. 2007. Endothelial-to-mesenchymal transition contributes to cardiac fibrosis. Nat Med 13: 952-961.
Zhang XH, Huang DP, Guo GL, Chen GR, Zhang HX, Wan L, Chen SY. 2008. Coexpression of VEGF-C and COX-2 and its association with lymphangiogenesis in human breast cancer. BMC Cancer 8: 4 .

Zhou Q, Brown J, Kanarek A, Rajagopal J, Melton DA. 2008. In vivo reprogramming of adult pancreatic exocrine cells to $\beta$-cells. Nature 455: 627-632.

Zumsteg A, Christofori G. 2009. Corrupt policemen: Inflammatory cells promote tumor angiogenesis. Curr Opin Oncol 21: 60-70.

Zumsteg A, Baeriswyl V, Imaizumi N, Schwendener R, Ruegg C, Christofori G. 2009. Myeloid cells contribute to tumor lymphangiogenesis. PLoS One 4: e7067. 


\section{$\&_{\mathrm{CSH}}^{\infty} \&$ Cold Spring Harbor

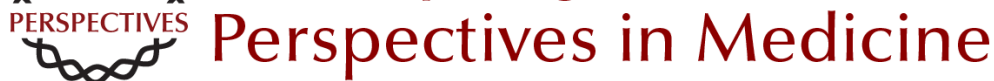

\section{Myeloid Cells and Lymphangiogenesis}

Adrian Zumsteg and Gerhard Christofori

Cold Spring Harb Perspect Med 2012; doi: 10.1101/cshperspect.a006494 originally published online February 21, 2012

\section{Subject Collection Angiogenesis}

Extracellular Matrix Regulation of Vascular Morphogenesis, Maturation, and Stabilization George E. Davis and Scott S. Kemp

Endothelial Cell-Pericyte Interactions in the Pathogenesis of Cerebral Cavernous Malformations (CCMs) Wang Min and Jenny Huanjiao Zhou

Lymphatic Clearance and Pump Function Jerome W. Breslin

Platelets and (Lymph)angiogenesis Harvey G. Roweth and Elisabeth M. Battinelli

Modeling Brain Vasculature Immune Interactions In Vitro Ruth Lyck, Hideaki Nishihara, Sidar Aydin, et al.

Human Endothelial Colony-Forming Cells Juan M. Melero-Martin

\section{The Beauty and Complexity of Blood Vessel} Patterning

Victoria L. Bautch and Yoh-suke Mukouyama

Endothelialitis, Microischemia, and

Intussusceptive Angiogenesis in COVID-19 Steven J. Mentzer, Maximilian Ackermann and Danny Jonigk
Regulation of the Blood-Brain Barrier in Health and Disease Cara C. Rada, Kanako Yuki, Jie Ding, et al.

Targeting Angiogenesis via Resolution of Inflammation

Abigail G. Kelly and Dipak Panigrahy

Notch Signaling in the Vasculature: Angiogenesis and Angiocrine Functions

Sana S. Hasan and Andreas Fischer

Signal Transduction and Gene Regulation in the Endothelium

Michel V. Levesque and Timothy Hla

Buttons and Zippers: Endothelial Junctions in

Lymphatic Vessels

Peter Baluk and Donald M. McDonald

Endothelial Cell Fate Determination: A Top Notch Job in Vascular Decision-Making

L.A. Naiche, Stephanie R. Villa and Jan K. Kitajewski

Leukocyte Trafficking in Lymphatic Vessels Aline Bauer, Hazal Tatliadim and Cornelia Halin

Lymphatic Tissue and Organ Engineering for In Vitro Modeling and In Vivo Regeneration Anna M. Kolarzyk, Gigi Wong and Esak Lee

For additional articles in this collection, see http://perspectivesinmedicine.cshlp.org/cgi/collection/ 